\title{
Avaliação do proteinograma sérico de cães com e sem sintomas neurológicos, naturalmente infectados por Leishmania chagasi
}

\section{Evaluation of serum proteinogram of dogs naturally infected with Leishmania chagasi with and without neurological symptoms}

\author{
Júlio Simões Marcondes, ${ }^{*}$ Francisco Leydson Formiga Feitosa, ${ }^{* *}$ Fabiana Augusta Ikeda-Garcia, ${ }^{* *}$ \\ Valéria Marçal Félix de Lima, ${ }^{* *}$ Sílvia Helena Venturoli Perri, ${ }^{* * *}$ Mary Marcondes Feitosa**
}

\begin{abstract}
Resumo
A leishmaniose visceral é uma antropozoonose causada por um protozoário do gênero Leishmania. A infecção no cão usualmente causa uma doença sistêmica crônica, que, clinicamente, é similar à humana. No Brasil, o Ministério da Saúde exige a eutanásia de animais portadores de leishmaniose visceral e não recomenda o tratamento dos mesmos. Entretanto, em muitos países esses animais são tratados, e a avaliação da resposta à terapia baseia-se nos títulos de anticorpos antileishmania e no proteinograma sérico. O presente trabalho teve como objetivos determinar a concentração de proteína total e suas frações eletroforéticas correlacionando-as com a presença de imunoglobulinas no soro de cães com leishmaniose visceral, com e sem acometimento neurológico. Foram utilizados dois grupos de animais, sendo o primeiro constituído de 18 cães portadores de leishmaniose visceral, sem evidências clínicas de envolvimento neurológico, e o segundo formado por 21 cães portadores de leishmaniose visceral com quadro neurológico. A proteína sérica total foi determinada através do método de biureto e em seguida realizou-se a migração eletroforética para separação das frações protéicas do soro sangüíneo. Ambos os grupos apresentaram uma intensa gamaglobulinemia, uma hipoalbuminemia e uma diminuição da fração alfaglobulina. A elevação dos níveis de gamaglobulina no grupo controle apresentou uma correlação com uma maior positividade no teste de ELISA no soro destes animais; $88,9 \%$ dos cães do grupo controle, contra apenas $28 \%$ de positivos no grupo com sintomatologia neurológica.
\end{abstract}

Palavras-chave: leishmaniose visceral, cães, eletroforese, IgG sérica.

\begin{abstract}
Visceral leishmaniasis is an antropozoonosis caused by a protozoan of the genus Leishmania. The infection in dogs usually cause a chronic systemic disease, that, clinically, is similar to human disease. In Brazil, Ministry of Health demands the euthanasia of infected animals and it doesn't recommend the treatment of the same ones, however, in many countries those animals are treated, and the evaluation of the answer to the therapy bases on the titles of antibodies and in serum proteinogram. The present study aimed to determine the total protein concentration, and their electrophoretic fractions, correlating them to the presence of immunoglobulin in the serum of dogs with visceral leishmaniasis, with and without neurological symptoms. Two groups of animals were used: the first was composed of 18 dogs with visceral leishmaniasis without clinical evidence of neurological involvement, and the second, composed of 21 dogs with visceral leishmaniasis and neurological symptoms. The total serum protein was done through biuret method and soon afterwards took place the electrophoretic separation. Both groups presented intense gammaglobulinemia, hypoalbuminemia, and decrease in the alpha globulin fraction. The increase in the gamma globulin levels in the control group showed correlation with the higher positive results for the ELISA test of sera of those dogs: $88.9 \%$ of dogs in the control group, as compared to only $28 \%$ positive results in the group with neurological symptoms.
\end{abstract}

Keywords: visceral leishmaniasis, dogs, electrophoresis, serum IgG.

\section{Introdução}

A leishmaniose visceral, também conhecida como Calazar, é uma antropozoonose, causada por um protozoário do gênero Leishmania. A infecção por L. (L.) chagasi no cão usualmente causa uma doença sistêmica crônica, que, clinicamente, é similar à humana. Em ambos os casos ocorrem febre irregular por longos períodos, anemia, perda progressiva de peso e caquexia no estágio final da doença (Ferrer, 1992; Ferrer et al., 1995; Ribeiro, 1997; Santa Rosa e Oliveira, 1997;

\footnotetext{
* Médico-veterinário residente - FMVZ - UNESP / Botucatu, SP.

** Departamento de Clínica, Cirurgia e Reprodução Animal - UNESP - Araçatuba, SP. Rua Clóvis Pestana, 793. CEP: 16050-680 - Araçatuba, SP. E-mail: feitosam@fmva.unesp.br

*** Pós-graduanda - FCAV - UNESP / Jaboticabal, SP.

**** Departamento de Apoio, Produção e Saúde Animal - UNESP - Araçatuba, SP.
} 
Slappendel e Ferrer, 1998; Noli, 1999). Os animais acometidos por leishmaniose visceral podem apresentar anemia, emaciação, alterações dermatológicas, onicogrifose, pneumonia, miocardite, distúrbios locomotores, diáteses hemorrágicas e alterações oculares (Keenan et al., 1984; Ferrer, 1992; Ferrer et al., 1995; Ciaramella et al., 1997; Ribeiro, 1997; Santa Rosa e Oliveira, 1997; Slappendel e Ferrer, 1998; Noli, 1999). Nos rins pode ocorrer deposição de imunocomplexos levando à glomerulonefrites, nefrites e insuficiência renal e, no fígado, os parasitas podem se multiplicar nos macrófagos hepáticos, produzindo uma hepatite ativa crônica e insuficiência hepática (Ferrer, 1992; Noli, 1999).

A leishmaniose canina pode ser considerada uma doença imunomediada devido à capacidade do parasita em modificar o sistema imunológico do hospedeiro. A resposta imune humoral na leishmaniose canina é muito exuberante, entretanto, ela é deletéria e não protetora. Como a leishmania é um parasita intracelular obrigatório, as defesas do hospedeiro são altamente dependentes da imunidade celular (Ferrer et al., 1995; Slappendel e Ferrer, 1998; Noli, 1999).

De acordo com grande parte dos autores, a maioria dos animais portadores de leishmaniose visceral apresenta hiperglobulinemia associada à hipoalbuminemia (Keenan et al., 1984; Ferrer, 1992; Ciaramella et al., 1997; Santa Rosa e Oliveira, 1997; Slappendel e Ferrer, 1998; Noli, 1999). As betaglobulinas aumentam na fase inicial da enfermidade seguidas pelas gamaglobulinas (Noli, 1999). A hiperglobulinemia é deletéria e não protetora, uma vez que a eliminação da infecção ocorre por ativação da imunidade celular e não humoral. Esse aumento no nível de globulinas séricas ocorre por uma indução de linfócitos T auxiliar do tipo 2 (Ta2), com conseqüente proliferação de linfócitos B e produção exacerbada de anticorpos. Um perigo potencial da regulação de linfócitos $T$ prejudicada e da atividade exuberante de linfócitos B é a geração de uma grande quantidade de imunocomplexos circulantes, causando danos em vários órgãos (Ferrer et al., 1995; Slappendel e Ferrer, 1998; Noli, 1999).

Para estabelecer o diagnóstico correto de leishmaniose visceral, é essencial conhecer a base dos testes diagnósticos, suas limitações e sua interpretação clínica (Ferrer, 1999). Existem basicamente três categorias de provas utilizadas para o diagnóstico: os métodos parasitológicos, onde se identifica a forma amastigota do parasita, os métodos sorológicos e, mais recentemente, os métodos moleculares (Ferrer, 1999).

No Brasil, o Ministério da Saúde exige a eutanásia de animais portadores de leishmaniose visceral e não recomenda 0 tratamento dos mesmos, uma vez que, apesar de ocorrer cura clínica, não existe comprovação de cura parasitológica e os animais, além de apresentarem recidiva do quadro clínico após alguns meses do término do tratamento, permanecem reservatórios da doença (Brasil, 2003). Entretanto, em muitos países esses animais são tratados, e a avaliação da resposta à terapia baseia-se nos títulos de anticorpos anti-leishmania e no proteinograma sérico. A normalização do proteinograma e a diminuição dos títulos são indicadores de boa resposta e prognóstico favorável (Ferrer, 2002).

Existem contradições na literatura quanto à patogênese da leishmaniose visceral no sistema nervoso central. Enquanto alguns autores relataram a observação de parasitas em todas as partes do corpo, exceto no sistema nervoso central (Noli,
1999), outros observaram intensa deposição de antígenos de leishmania e imunoglobulinas nos espaços intersticial e intravascular do plexo coróide de cães com leishmaniose visceral, levando a uma coroidite (García-Alonso et al., 1996; Nieto et al., 1996; Slappendel e Ferrer, 1998). A origem dos anticorpos no líquor de animais com leishmaniose ainda não está totalmente esclarecida, mas acredita-se que eles provenham do sangue, devido à lesão da barreira hematoencefálica. No entanto, não se pode excluir a possibilidade de que os antígenos de leishmanias induzam à formação intratecal de anticorpos (García-Alonso et al., 1996; Nieto et al., 1996; Slappendel e Ferrer, 1998; Noli, 1999). As manifestações neurológicas descritas em animais portadores de leishmaniose visceral incluem convulsões, alterações visuais, paralisia de nervos cranianos e alterações locomotoras, sintomas que devem incluir em seu diagnóstico diferencial outras enfermidades infecciosas, tais como toxoplasmose, neosporose, erliquiose, babesiose e cinomose (Feitosa et al., 2005).

\section{Objetivos}

Os objetivos do presente trabalho foram determinar a concentração de proteína total, e suas frações eletroforéticas correlacionando-as com a presença de imunoglobulinas no soro de cães com leishmaniose visceral, com e sem envolvimento neurológico.

\section{Materiais e métodos}

\section{Animais utilizados}

Foram utilizados dois grupos de animais. O primeiro, constituído de 18 cães portadores de leishmaniose visceral, sem evidências clínicas de envolvimento neurológico, e o segundo formado por 21 cães portadores de leishmaniose visceral com quadro neurológico, encaminhados ao Hospital Veterinário do Curso de Medicina Veterinária da Universidade Estadual Paulista "Júlio de Mesquita Filho"- UNESP - Campus Araçatuba, durante o período de junho de 2000 a maio de 2002.

O diagnóstico de leishmaniose visceral foi realizado através do exame citológico de punção biópsia aspirativa de linfonodo e/ou através de sorologia pelo método de ELISA. Todos os animais foram submetidos a um exame físico e neurológico completo, e os dados anotados em fichas individuais. Nos animais com sintomas neurológicos, foi pesquisada a presença de anticorpos contra Babesia sp., Ehrlichia sp., Toxoplasma gondii e Neospora sp., além da presença de corpúsculos de inclusão do vírus da cinomose.

\section{Colheita de sangue total}

A colheita de sangue foi realizada após assepsia local por punção da veia jugular, utilizando-se, para tanto, agulhas $25 \mathrm{x}$ $8 \mathrm{~mm}$, acopladas a tubos vacutainer siliconizados. O sangue, em um volume total de $20 \mathrm{~mL}$, foi mantido à temperatura ambiente até a coagulação e retração visível do coágulo. Em seguida, sofreu centrifugação a $960 \mathrm{~g}$, durante cinco minutos, para melhor separação do soro. Este, por sua vez, foi transferido para frascos de plásticos apropriados com o auxílio de pipeta automática e congelado imediatamente a $-20^{\circ} \mathrm{C}$, até o momento do seu processamento. 
Proteína sérica total e frações eletroforéticas: a proteína sérica total foi determinada pelo método de biureto preconizado por Gornal et al. (1949) utilizando-se, para tanto, um espectrofotômetro digital SB-190, marca CELM. A migração eletroforética para separação das frações protéicas do soro sangüíneo foi efetuada segundo as técnicas descritas por Friedman (1961) e Kremers et al. (1967), com as seguintes modificações: em cubas para eletroforese Colab, foram estendidas fitas de acetato de celulose (Cellogel) de 2,5 x $14,0 \mathrm{~cm}$, umedecidas com solução tampão; sobre as mesmas foi colocado, na extremidade correspondente ao ânodo, 1 microlitro da amostra de soro. Ao sistema preparado com tampão barbital (Colab), de pH 8,6 e força iônica correspondente a 0,05, aplicou-se uma corrente de 220 volts para cada corrida eletroforética, durante 35 minutos. Após a separação das frações protéicas, fez-se a coloração das tiras, com Ponceau "S" (corante de Ponceau em solução a 0,2\% em ácido tricloroacético a $3 \%$ ), durante 15 minutos, seguida da lavagem com solução de ácido acético a 5\% em água destilada e posterior desidratação, durante dois minutos, com metanol. Na fase seguinte, as tiras foram diafanizadas, durante dois minutos, com a seguinte solução: 83 partes de metanol, 16 partes de ácido acético glacial e uma parte de glicerina p.a. As tiras, posteriormente, foram estendidas entre as placas de vidro, e mantidas aquecidas em estufa a 80 - 90 C, até a sua completa transparentização. A separação e quantificação das diferentes frações protéicas foram realizadas por fracionamento manual em um aparelho de densitometria, (Densitômetro modelo BTS 325, Biosystems).

Imunoglobulina G sérica: A presença de IgG no soro foi determinada pela técnica de ELISA. As microplacas foram cobertas com antígeno total de parasita numa concentração de $20 \mathrm{mg} / \mathrm{ml}$ em tampão carbonato 0,05 M, pH 9,6 e incubadas overnight a $4^{\circ} \mathrm{C}$. Após a lavagem com PBS-tween por três vezes, as placas foram bloqueadas com $200 \mathrm{ml}$ de PBS-BSA $1 \%$ e incubadas à temperatura ambiente durante duas horas. Após nova lavagem com PBS-tween por três vezes, $100 \mathrm{ml}$ do soro controle positivo, do soro controle negativo (animal de área não endêmica saudável) e das amostras dos soros dos animais portadores de leishmaniose visceral com e sem quadro neurológico diluídas 1:400 em PBS contendo 0,05\% de tween 20 e 1\% de BSA foram adicionadas a cada poço e incubadas por três horas à temperatura ambiente. Após quatro lavagens com PBS-tween 20 , foram adicionados à placa $100 \mathrm{ml}$ de anticorpo anti-IgG de cão, marcado com peroxidase previamente titulado. Após a incubação por uma hora em temperatura ambiente, a placa foi novamente lavada quatro vezes com PBS-tween 20 e foram adicionados $100 \mathrm{ml}$ de uma solução contendo substrato $\operatorname{OPD}(0,4 \mathrm{mg} / \mathrm{ml})$ em diluente apropriado. A reação foi parada adicionando-se a cada poço $50 \mathrm{ml} \mathrm{de} \mathrm{H}_{2} \mathrm{SO}_{4}$ $1 \mathrm{M}$ e a densidade óptica (D.O.) foi avaliada a $492 \mathrm{~nm}$, utilizando o leitor de ELISA (Labsystems Multiskan EX). Os resultados foram expressos pela média da densidade óptica obtida dos soros em triplicata.

\section{Análise estatística}

Os dados obtidos foram tabulados e submetidos à análise estatística, apresentando-se a estatística descritiva (média, mediana e desvio-padrão) e realizando-se a comparação entre variáveis.

As comparações entre os dois grupos foram efetuadas de duas maneiras, dependendo do tipo de variável analisada. Teste t para duas amostras independentes (ZAR, 1998) usado no caso de variáveis cuja tendência central pode ser adequadamente representada pela média $(x)$. Inicialmente foi realizado o teste de homogeneidade de variâncias dos dois grupos, para, a seguir, ser calculada a estatística t, utilizando a variância comum dos dois grupos (no caso de homogeneidade de variâncias) ou não (no caso de heterogeneidade das variâncias). Neste caso os graus de liberdade foram corrigidos. Prova não-paramétrica de Mann Whitney (ZAR, 1998) usada para variáveis cuja tendência central foi mais adequadamente representada pela mediana (md) do grupo. Teste do $X_{2}$ ou teste exato de Fisher (ZAR, 1998) quando ocorreram freqüências esperadas inferiores a 5, para verificar associação entre as variáveis classificatórias. As estatísticas calculadas foram consideradas significativas quando $p<0,05$.

\section{Resultados}

As principais alterações neurológicas observadas foram convulsões generalizadas em vários animais; alterações visuais tais como cegueira, anisocoria e midríase bilateral; paralisia de nervos cranianos; sinais de envolvimento vestibular e cerebelar (inclinação da cabeça, nistagmo, incoordenação motora, quedas, tremor de intenção); tetraparesia e tetraplegia; vocalização; andar em círculos e episódios de perseguição à cauda. Os sinais observados denotam um envolvimento central generalizado, atingindo córtex cerebral, tronco encefálico, cerebelo e medula. Nenhum animal avaliado apresentou presença de anticorpos contra Babesia sp., Ehrlichia sp., Toxoplasma gondii, Neospora sp. e nem presença de corpúsculos de inclusão do vírus da cinomose, descartando a possibilidade da participação destas enfermidades no desenvolvimento dos sintomas neurológicos.

As determinações da concentração de proteína sérica total, bem como seu respectivo fracionamento eletroforético, dos cães com leishmaniose visceral sem e com sintomatologia neurológica, encontram-se apresentados na Tabela 1.

Tabela 1: Média $(\overline{\mathrm{X}})$, desvio-padrão (s) e mediana $(\mathrm{md})$ para proteína total, albumina (ALB), alfaglobulina (ALFA), betaglobulina (BETA) e gamaglobulina (GAMA) de cães portadores de leishmaniose visceral sem sintomatologia neurológica (controle) e com sintomatologia neurológica (neurológico).

\begin{tabular}{cccccc}
\hline \multirow{2}{*}{ VARIÁVEL } & \multicolumn{2}{c}{ CONTROLE } & \multicolumn{2}{c}{ NEUROLÓGICO } & \multirow{2}{*}{$\mathbf{p}$} \\
\cline { 2 - 5 } & $\bar{X} \pm \mathbf{s}$ & Md & $\bar{X} \pm \mathbf{s}$ & Md & \\
\hline PT (g/dL) & $8,42 \pm 1,55$ & 8,185 & $6,60 \pm 1,46$ & 6,27 & $0,0011^{(1)}$ \\
ALB (g/dL) & $1,92 \pm 0,59$ & 1,895 & $2,03 \pm 0,65$ & 1,78 & $0,5775^{(1)}$ \\
ALFA (g/dL) & $0,62 \pm 0,43$ & 0,39 & $0,64 \pm 0,34$ & 0,62 & $0,6558^{(2)}$ \\
BETA (g/dL) & $1,11 \pm 0,67$ & 0,835 & $1,24 \pm 0,71$ & 1,36 & $0,6204^{(2)}$ \\
GAMA (g/dL) & $4,77 \pm 2,29$ & 4,83 & $2,69 \pm 1,87$ & 1,98 & $0,0043^{(2)}$ \\
\hline
\end{tabular}

$\begin{array}{ll}\text { (1) nível descritivo do teste } t & \text { (2) nível descritivo do teste de Mann-Whitney }\end{array}$ 


\section{Imunoglobulina G sérica}

Os resultados da pesquisa de imunoglobulina G sérica dos animais portadores de leishmaniose visceral, sem e com sintomatologia nervosa, são apresentados na Tabela 2.

Tabela 2: Determinação de imunoglobulina G no soro de cães portadores de leishmaniose visceral com e sem sintomatologia neurológica. Número, percentagem de animais e estatística calculada. (Araçatuba - SP, 2003)

\begin{tabular}{lcccccccc}
\hline \multirow{2}{*}{ Variável } & Categoria & \multicolumn{2}{c}{ Controle } & Neurológico & \multicolumn{2}{c}{ Total } & \multirow{2}{*}{$\mathbf{p}^{(1)}$} \\
\cline { 3 - 7 } & & $\mathbf{N}$ & $\%$ & $\mathbf{N}$ & $\%$ & $\mathbf{N}$ & $\%$ & \\
\hline \multirow{3}{*}{ IgG no Soro } & Negativo & 2 & 11,1 & 10 & 71,4 & 12 & 37,5 & \\
& Positivo & 16 & 88,9 & 4 & 28,6 & 14 & 62,5 & 0,001 \\
& Total & 18 & 100,0 & 14 & 100,0 & 26 & 100,0 &
\end{tabular}

(1) nível descritivo do teste Qui-quadrado.

\section{Discussão e conclusão}

Verificou-se uma diferença estatisticamente significativa entre os valores médios de proteína sérica total dos dois grupos de animais, sendo que os cães do grupo com sintomatologia neurológica apresentaram valores inferiores aos do grupo controle, mas, dentro da faixa de normalidade descrita por Coles (1984) e Kaneko (1997). A elevação dos níveis de proteína sérica total nos animais do grupo controle se deu devido a um aumento dos níveis de gamaglobulina, fato que foi evidenciado pela diferença estatisticamente significativa entre os dois grupos para essa fração eletroforética. Entretanto, apesar da diferença entre os dois grupos, ambos apresentavam uma intensa gamaglobulinemia, quando comparados aos valores de referência descritos por Coles (1984), cujos valores médios são de $0,8 \mathrm{~g} / \mathrm{dL}$. Não foram constatadas diferenças estatisticamente significativas entre os dois grupos de animais no que diz respeito às outras frações eletroforéticas (albumina, alfaglobulina e betaglobulina). Nos dois grupos de cães observou-se uma hipoalbuminemia e uma diminuição da fração alfaglobulina, segundo os valores de referência citados por Coles (1984). Já os valores de betaglobulina encontravam-se dentro da faixa de normalidade descrita pelos referidos autores, discordando dos relatos de Noli (1999), os quais afirmaram que essa fração eletroforética encontra-se elevada em animais com leishmaniose visceral.

No presente experimento os valores de proteína sérica total e seu fracionamento eletroforético na maioria dos animais do grupo controle corroboram os dados da literatura (Keenan et al., 1984; Ferrer, 1992; Ciaramella et al., 1997; Santa Rosa e Oliveira, 1997; Slappendel e Ferrer, 1998; Noli, 1999), os quais afirmaram que cães com leishmaniose visceral apresentam uma hiperproteinemia acompanhada de uma hipoalbuminemia, com discreta diminuição das frações alfa e beta e uma marcante gamaglobulinemia (Figura 1). A diminuição da concentração de albumina sérica pode ser resultante de distúrbio da síntese hepática, acompanhando doenças hepáticas crônicas (Ciaramella et al., 1997), da perda renal em casos de doença glomerular, ou, até, associada a uma série de doenças crônicas que se fazem acompanhar por caquexia, como no caso da leishmaniose visceral (Ciaramella et al., 1997; Ferrer, 1992)

Já no grupo de animais que apresentaram sinais neurológicos, apesar da proteína sérica total encontrar-se dentro da faixa de normalidade na maioria dos cães, quando do fracionamento eletroforético observou-se também uma diminuição das frações albumina, alfa e beta e uma hipergamaglo-bulinemia. A elevação dos níveis de gamaglobulina no grupo controle apresentou uma correlação com uma maior positividade no teste de ELISA no soro destes animais; $88,9 \%$ dos cães do grupo controle, contra apenas $28 \%$ de positivos no grupo com sintomatologia neurológica. $\mathrm{O}$ fato de os animais do grupo neurológico apresentarem menor positividade ao ELISA pode ser explicado pela menor gamaglobulinemia observada nos mesmos. Grande parte dos animais com sintomatologia neurológica não apresentava envolvimento sistêmico da doença. Isto poderia justificar o fato desses cães possuírem sorologia negativa, por ainda não terem realizado soroconversão devido a uma fase mais precoce da doença em relação aos do grupo controle, que apresentavam uma evolução mais longa. Apesar de muitos animais apresentarem resultado negativo na avaliação sorológica através de ELISA, estes cães foram positivos quando da punção biópsia aspirativa de linfonodos e/ou medula óssea, apresentando formas amastigotas de Leishmania sp. no esfregaço. Segundo a literatura, alguns animais apresentam-se soronegativos por toda a evolução da doença (Ferrer et al., 1995), apesar de se esperar que os mesmos tenham altos títulos de anticorpos, uma vez que a imunidade celular encontra-se diminuída, enquanto a humoral encontra-se exacerbada em cães portadores de leishmaniose visceral com sintomas clínicos.

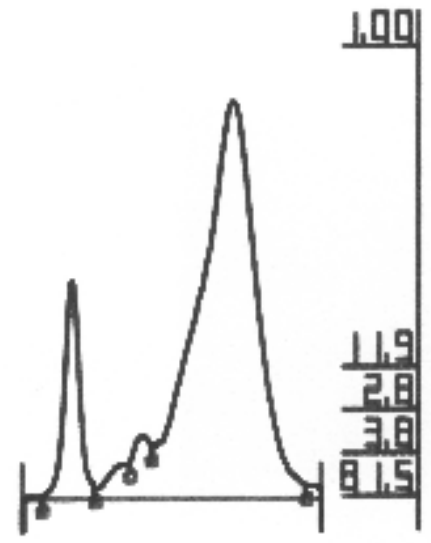

Figura 1: Fracionamento eletroforético de cão naturalmente infectado por Leishmania chagasi. 


\section{Agradecimentos}

Agradecemos à Fundação de Apoio à Pesquisa do Estado de São Paulo (FAPESP) pelo suporte técnico e apoio financeiro.

\section{Referências}

BRASIL. Ministério da Saúde. Secretaria de Vigilância em Saúde. Departamento de Vigilância Epidemiológica. Manual de vigilância e controle da leishmaniose visceral. Brasília, DF: Ministério da Saúde, 2003, $120 \mathrm{p}$.

CIARAMELLA, P.; OLIVA, G.; DE LUNA, R.; GRADONI, L.; AMBROSIO, R.; CORTESE, L.; SCALONE, A.; PERSECHINO, A. A retrospective clinical study of canine leishmaniasis in 150 dogs naturally infected by leishmania infantum. Vet. Rec., v. 141, p. 539-543, 1997.

COLES, E. H. Veterinary clinical pathology. Philadelphia:W.B.Saunders, 1984. $566 \mathrm{p}$.

FEITOSA, M. M.; IKEDA, F. A.; BONELLO, F. L.; CIARLINI, P. C.; GONÇALVES, M. E.; LIMA, V. M. F.; PERRI, S. H. V. Avaliação liquórica de cães, com e sem sintomatologia neurológica, naturalmente acometidos por leishmaniose visceral. Veterinária Notícias, Uberlândia, v. 11, n. 2, p. 61-69, 2005.

FERRER, L. Leishmaniasis. In: KIRK, R. W.; BONAGURA, J. D. Kirk's Current Veterinary Therapy XI. Philadelphia:W. B. Saunders, 1992, p. 266-270.

FERRER, L. Clinical aspects of canine leishmaniasis. INTERNATIONAL CANINE LEISHMANIASIS FORUM, 1999, Barcelona. Proceedings..., 1999, p. 6-10.

FERRER, L. Canine leishmaniosis: evaluation of the immunocompromised patient. WSAVA Congress, 2002, Granada. Proceedings..., 2002, p. 262-265.

FERRER, L.; AISA, M. J.; ROURA, X.; PORTÚS, M. Serological diagnosis and treatment of canine leishmaniasis. Vet. Rec., v. 136, p. 514-516, 1995.

FRIEDMAN, H. S. A standardized procedure for serum protein eletrophoresis on cellulose acetate membrane strips. Clin. Chim. Acta, v. 6, p. $775-781,1961$.
GARCÍA-ALONSO, M.; NIETO, A. G.; BLANCO, A.; REQUENA, J. M.; ALONSO, C.; NAVARRETE, I. Presence of antibodies in the aqueous humour and cerebrospinal fluid during Leishmania infections in dogs. Pathological features at the central nervous system. Parasite Immunol., v. 18, p. 539-546, 1996.

GORNALL, A. G.; BARDAWILL, C. J.; DAVID, M. M. Determination of serum protein by means of biuret reaction. J. Biol. Chem., v. 177, p. 751-766, 1949.

KANEKO, J. J. Serum proteins and dysproteinemias. In: KANEKO, J.J.; HARVEY, J.W.; BRUSS, M.L. Clinical biochemistry of domestic animals. 5. ed. San Diego: Academic Press, 1997, p. 117-138.

KEENAN, C. M.; HENDRICKS, L. D.; LIGHTNER, L.; WEBSTER, H. K.; JOHNSON, A. J. Visceral Leishmaniasis in the German Shepherd Dog. I. Infection, Clinical Disease, and Clinical Pathology. Vet. Pathol., v. 21, p. 74-79, 1984.

KREMERS, B.;BRIERE, R.; BATASAKIS, J. G. Reflectance densitometry of cellulose acetate protein electrophoresis. Am. J. Med. Technol., v. 33, p. 28-34, 1967.

NIETO, C. G.; VIÑUELAS, J.; BLANCO, A.; GARCÍA-ALONSO, M.; VERDUGO, S. G.; NAVARRETE, I. Detection of Leishmania infantum amastigotes in canine choroid plexus. Vet. Rec., v. 139, p. 346-347, 1996. NOLI, C. Leishmaniosis canina. Waltham Focus, v. 9, n. 2, p. 16-24, 1999.

RIBEIRO, V. M. Leishmanioses. Revista do Conselho Federal de Medicina Veterinária. Ano 3, n. 11, p. 13-14, 1997.

SANTA ROSA, I. C. A.; OLIVEIRA, I. C. S. Leishmaniose visceral: breve revisão sobre uma zoonose reemergente. Clínica Veterinária, ano II, n. 11, p. 24-28, 1997.

SLAPPENDEL, R. J.; FERRER, L. Leishmaniasis. In: GREENE, C. E. Clinical Microbiology and Infectious Diseases of the Dog and Cat. Philadelphia: W. B.Saunders Co., 1998. p. 450-458.

ZAR, J. H. Biostatistical analysis. 4. ed. New Jersey: Prentice-Hall, 1998, $930 \mathrm{p}$. 